\title{
Quantifying the roles of ocean circulation and biogeochemistry in governing ocean carbon-13 and atmospheric carbon dioxide at the last glacial maximum
}

\author{
A. Tagliabue ${ }^{1}$, L. Bopp ${ }^{1}$, D. M. Roche ${ }^{1,2}$, N. Bouttes ${ }^{1}$, J.-C. Dutay ${ }^{1}$, R. Alkama ${ }^{1,3}$, M. Kageyama ${ }^{1}$, E. Michel ${ }^{1}$, and \\ D. Paillard ${ }^{1}$ \\ ${ }^{1}$ Laboratoire des Sciences du Climat et de l'Environnement, IPSL-CEA-CNRS-UVSQ, 91191 Gif sur Yvette, France \\ ${ }^{2}$ Department of Palaeoclimatology and Geomorphology, Faculty of Earth and Life Sciences, Vrije Universiteit Amsterdam, \\ De Boelelaan 1085, 1081 HV Amsterdam, The Netherlands \\ ${ }^{3}$ Centre National de Recherches Météorologiques (CNRM), 42 Avenue Coriolis, 31057 Toulouse, France
}

Received: 14 May 2009 - Published in Clim. Past Discuss.: 20 May 2009

Revised: 28 September 2009 - Accepted: 19 October 2009 - Published: 18 November 2009

\begin{abstract}
We use a state-of-the-art ocean general circulation and biogeochemistry model to examine the impact of changes in ocean circulation and biogeochemistry in governing the change in ocean carbon-13 and atmospheric $\mathrm{CO}_{2}$ at the last glacial maximum (LGM). We examine 5 different realisations of the ocean's overturning circulation produced by a fully coupled atmosphere-ocean model under LGM forcing and suggested changes in the atmospheric deposition of iron and phytoplankton physiology at the LGM. Measured changes in carbon-13 and carbon-14, as well as a qualitative reconstruction of the change in ocean carbon export are used to evaluate the results. Overall, we find that while a reduction in ocean ventilation at the LGM is necessary to reproduce carbon-13 and carbon-14 observations, this circulation results in a low net sink for atmospheric $\mathrm{CO}_{2}$. In contrast, while biogeochemical processes contribute little to carbon isotopes, we propose that most of the change in atmospheric $\mathrm{CO}_{2}$ was due to such factors. However, the lesser role for circulation means that when all plausible factors are accounted for, most of the necessary $\mathrm{CO}_{2}$ change remains to be explained. This presents a serious challenge to our understanding of the mechanisms behind changes in the global carbon cycle during the geologic past.
\end{abstract}

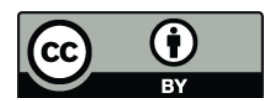

Correspondence to: A. Tagliabue (alessandro.tagliabue@ @1sce.ipsl.fr)

\section{Introduction}

Reproducing past changes in the global carbon cycle is a key test of our understanding of the Earth's climate system and, as such, explaining the documented changes in atmospheric gases and geochemical proxies that occurred during the last glacial maximum (LGM) remains an enduring challenge. Since the carbon stored in the terrestrial biosphere likely declined (e.g., Bird, et al., 1994; Sigman and Boyle, 2000), the ocean is believed to be responsible for the $80 \mathrm{ppm}$ reduction in atmospheric carbon dioxide $\left(p \mathrm{CO}_{2 \mathrm{~atm}}\right)$ measured in ice cores (Petit et al., 1999) at the LGM. In reproducing this change, only $\sim 50 \mathrm{ppm}$ needs to be explained by a given hypothesis, as the remainder can be accounted for by subsequent deep-ocean carbonate compensation (e.g., Brovkin et al., 2007). In parallel to reduced $p \mathrm{CO}_{2 \mathrm{~atm}}$, sediment cores have shown that the gradient in $\delta^{13} \mathrm{C}_{\mathrm{DIC}}$ between upper and deeper waters (as measured by benthic foraminifera) was $50 \%$ greater at the LGM (e.g., Duplessy et al., 1988; Curry and Oppo, 2005). Accordingly, $p \mathrm{CO}_{2 \mathrm{~atm}}$ and the $\delta^{13} \mathrm{C}_{\text {DIC }}$ gradient provide two constraints for hypotheses that seek to explain the processes that resulted in the LGM climate and $p \mathrm{CO}_{2 \mathrm{~atm}}$.

Since the LGM was typified by changes in both ocean circulation (Lynch-Stieglitz et al., 2007) and dust deposition of the micronutrient iron (Petit et al., 1999; Martin, 1990; Mahowald et al., 2006), modified $p \mathrm{CO}_{2 \text { atm }}$ and $\delta^{13} \mathrm{C}_{\mathrm{DIC}}$ potentially reflect changes in productivity and/or circulation (e.g., Brovkin et al., 2007; Lynch-Stieglitz et al., 2007; Toggweiler, 1999, 2006; Michel et al., 1995; Bopp et al., 2003). This

Published by Copernicus Publications on behalf of the European Geosciences Union. 
would be manifested by changes in the ocean's solubility and/or biological pumps (driven by physical and biological processes). Colder sea surface temperatures can increase the solubility of $\mathrm{CO}_{2}$ in the ocean at the LGM, while ocean productivity could be stimulated by additional iron from dust (Martin, 1990) or by changes in phytoplankton stoichiometry that more efficiently produce organic carbon per unit macronutrient (Broecker, 1982; Omta et al., 2006). The widely measured changes in $\delta^{13} \mathrm{C}_{\mathrm{DIC}}$ are, thus, an important additional constraint on hypotheses that seek to explain LGM $p \mathrm{CO}_{2 \mathrm{~atm}}$.

Most models that have investigated LGM $p \mathrm{CO}_{2 \mathrm{~atm}}$ and $\delta^{13} \mathrm{C}_{\mathrm{DIC}}$ have been box models or models of intermediatecomplexity (IC-models) (e.g., Toggweiler, 1999, 2006; Brovkin et al., 2007), which permit a wide exploration of parameter space, but sacrifice degrees of physical and/or biogeochemical realism that preclude a detailed spatial comparison with observations. 3-D ocean-general-circulation and biogeochemistry models (OGCBMs) can represent the effect of LGM climate on circulation and the subsequent impact on biogeochemistry in a more mechanistic sense (e.g., Bopp et al., 2003; Kurahashi-Nakamura et al., 2007) and can also simulate well-measured paleo-proxies such as $\delta^{13} \mathrm{C}$ and $\Delta^{14} \mathrm{C}$. Such a procedure permits a thorough spatial comparison of the $\delta^{13} \mathrm{C}_{\mathrm{DIC}}$ distribution resulting from a given LGM atmosphere-ocean scenario to observations and provides confidence in model results.

Here we use a state-of-the-art OGCBM to examine how $p \mathrm{CO}_{2 \mathrm{~atm}}$ and $\delta^{13} \mathrm{C}_{\mathrm{DIC}}$ respond to changes in ocean circulation and dust deposition. We constrain the modelled LGM $\Delta \delta^{13} \mathrm{C}_{\text {DIC }}$ using 133 observations from benthic foraminifera. Our results allow us to delineate differing roles for circulation and biology in governing LGM $\delta^{13} \mathrm{C}$ and $p \mathrm{CO}_{2 \mathrm{~atm}}$, but highlight important shortcomings in capturing the required LGM change in $p \mathrm{CO}_{2 \text { atm }}$ using existing hypotheses.

\section{Methods}

\subsection{Ocean biogeochemical model}

Our OGCBM PISCES (Aumont and Bopp, 2006) simulates nanophytoplankton and diatoms, meso-/micro-zooplankton, small/large detritus, carbon-13, carbon-14, calcium carbonate, biogenic silica, dissolved-inorganic-carbon, carbonate, dissolved-organic-carbon, nitrate, phosphate, silicic acid and iron. Fixed organic matter production ratios are employed for nitrogen and phosphorous, while ratios of both silica, and iron, to carbon vary as a function of the phytoplankton group and environmental variables. The PISCES model has previously been evaluated and used for a wide variety of studies concerning historical and future climate (e.g., Bopp et al., 2003; Aumont and Bopp, 2006; Tagliabue and Bopp, 2008; Tagliabue et al., 2008).
We explicitly resolve carbon-13 in the existing 3 dissolved and 7 particulate carbon pools, with fractionation occurring during photosynthesis, precipitation of calcite, gas exchange and carbonate chemistry (Tagliabue and Bopp, 2008). We parameterize photosynthetic fractionation (\%o) to be a function of the $\mathrm{CO}_{2}$ (aq) concentration and the specific growth rate $(\mu)$ of each phytoplankton group. In an attempt to account for the influence of cell size on photosynthetic fractionation, as well as the observed minimum at high values of $\mu / \mathrm{CO}_{2}$ (aq), we restrict the variation in photosynthetic fractionation to between 5 and 20, and 10 and 26\%o for diatoms and nanophytoplankton, respectively. Calcite formation has a fixed fractionation of $1 \%$. Fractionation during gas exchange, and the conversion of $\mathrm{CO}_{2}(\mathrm{aq})$ to DIC, are a function of temperature and the proportion of the DIC present as $\mathrm{CO}_{3}^{2-}$. We refer readers to Tagliabue and Bopp (2008) for a complete description of the model and an evaluation against observations for the historical period (1860 to 2000). We note that we begin our simulations with the configuration from Tagliabue and Bopp (2008) that best matches modern deep ocean $\delta^{13} \mathrm{C}_{\text {DIC }}$ (i.e., PISCES-D in the notation of Tagliabue and Bopp (2008), see Supplementary Fig. 1: http://www. clim-past.net/5/695/2009/cp-5-695-2009-supplement.pdf).

${ }^{14} \mathrm{C}$ simulations followed the OCMIP protocol (http: //www.ipsl.jussieu.fr/OCMIP/) and were conducted for 3000 years, assuming LGM values for $p \mathrm{CO}_{2 \mathrm{~atm}}$, salinity and alkalinity and constant atmospheric ${ }^{14} \mathrm{C}$ production.

\subsection{Physical model}

The physical model coupled to PISCES is based on the ORCA2 global ocean model configuration of OPA version 8.2 (Madec et al., 1998) and also includes a dynamicthermodynamic sea-ice model (Timmermann et al., 2003). The mean horizontal resolution is approximately $2^{\circ}$ by $2^{\circ}$ cos (latitude) and the meridional resolution is enhanced to $0.5^{\circ}$ at the Equator. The model has 30 vertical levels; with an increment that increases from $10 \mathrm{~m}$ at the surface to $500 \mathrm{~m}$ at depth (12 levels are located in the first $125 \mathrm{~m}$ ). Our simulations were forced by the output from the IPSL coupled atmosphere-ocean climate model under LGM forcing in terms of the radiative properties of atmospheric gases and orbital forcing, with a LGM land/ocean mask and LGM topography and ice sheets (see Sect. 2.4). As such, this produces changes in physical transport and temperature and salinity properties of the ocean that can be used to force PISCES offline.

\subsection{The intermediate complexity model CLIMBER-2}

The IC-model CLIMBER-2 (Petoukhov et al., 2000) simulates the atmosphere, ocean and land biosphere. The atmospheric model has a coarse resolution of $10^{\circ}$ and $51^{\circ}$ in latitude and longitude, respectively. CLIMBER-2 includes a zonally averaged ocean model with a $2.5^{\circ}$ meridional 


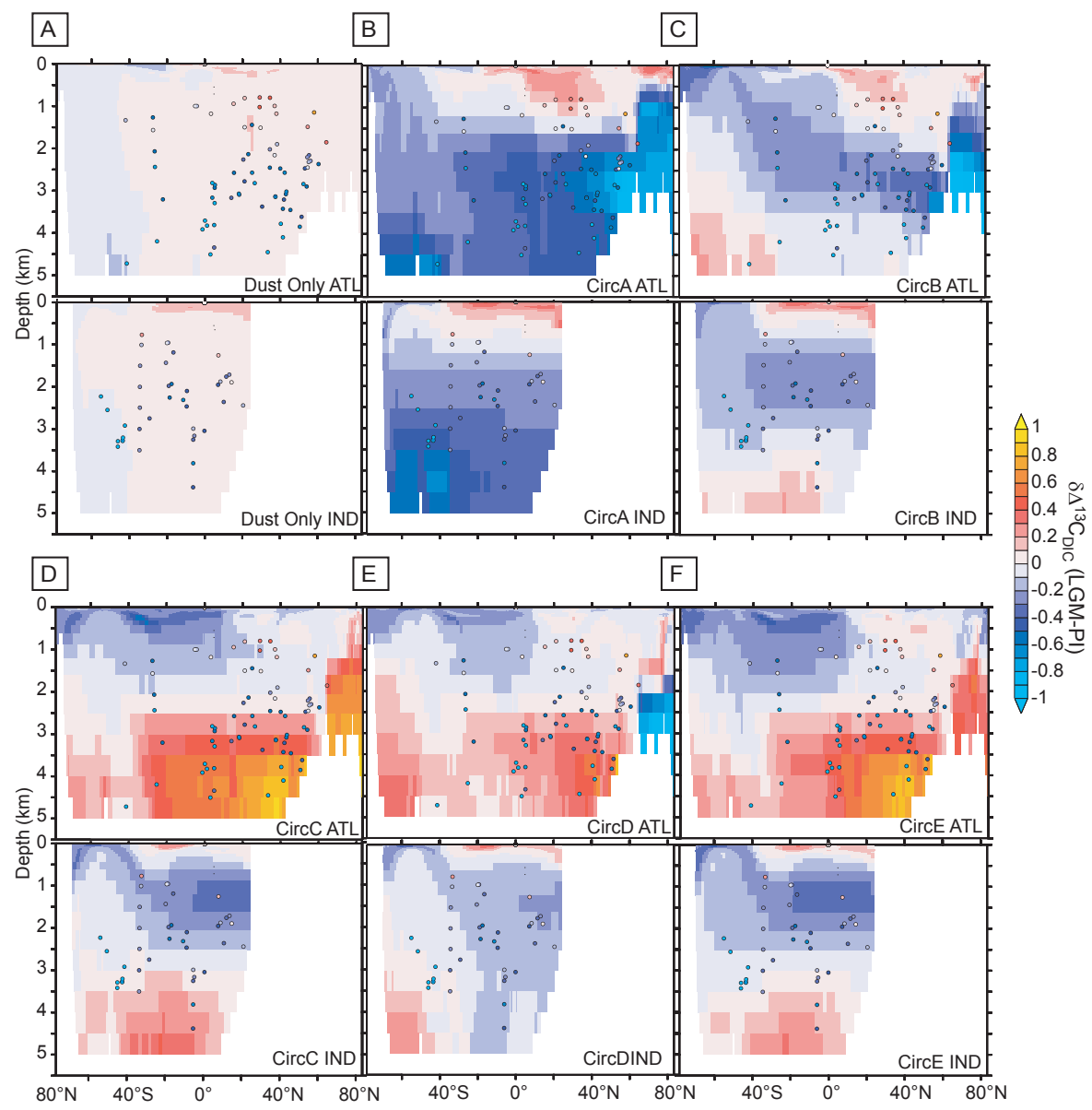

Fig. 1. Zonal changes in $\delta^{13} \mathrm{C}_{\mathrm{DIC}}(\%)$ between the pre-industrial and LGM periods (LGM-PI) for the Atlantic and Indian Ocean basins, with circles representing benthic foraminifera $\Delta \delta^{13} \mathrm{C}_{\text {DIC }}$ observations from the MOTIF database. We highlight the role of LGM dust deposition from Mahowald et al. (2006) and 5 different realisations of ocean circulation from the IPSL coupled model under LGM forcing that modify North Atlantic and Southern Ocean ventilation to varying degrees (Table 1). (A) LGM dust deposition under a pre-industrial ocean circulation, (B) CircA, (C) CircB, (D) CircC, (E) CircD, and (F) CircE. The PI state of the model for these basins is presented in Supplementary Fig. 1 (see http://www.clim-past.net/5/695/2009/cp-5-695-2009-supplement.pdf).

resolution and 20 uneven vertical levels, a sea-ice model and the carbon system (including carbon-13), as well as a simplistic representation of ocean biota. Due to its intermediate complexity, we decided to use CLIMBER-2 to examine the robustness of the major conclusions from our OGCBM with simulations of 20000 years (i.e., to equilibrium). Ocean circulation in CLIMBER-2 was modified via additions of freshwater, which permitted us to evaluate the impact of changes in ocean ventilation on $\delta^{13} \mathrm{C}_{\mathrm{DIC}}$ in a similar fashion as for the OGCBM.

\subsection{Experimental strategy}

We employed the OGCBM PISCES to prognostically simulate ocean biogeochemistry, including carbon-13 and carbon14 , when forced by a variety of LGM circulation schemes that arise from the fully coupled IPSL model (see: Sect. 2.2,
Table 1). In all LGM simulations, snow accumulates on the ice-sheets and this freshwater sink has to be compensated in order to obtain stable simulations. Therefore, simulations differ in the regions chosen for the redistribution of freshwater (CircD and $\mathrm{CircE}$ ) and different degrees of freshwater forcing (CircA, CircB, CircC), which results in the variable overturning circulations summarized in Table 1 (Alkama et al., 2007; Arsouze et al., 2008; Kageyama et al., 2009).

We use an estimation of LGM dust deposition that is constrained by the sediment record and iron supply increases 1.5-fold, primarily in the Southern Ocean (SO) Atlantic sector (Mahowald et al., 2006). Pre-industrial and LGM dust deposition fields assumed Fe to be $3.5 \%$ of dust, with a solubility of $0.5 \%$ (Tagliabue et al., 2008). Shelf iron supply was recalculated assuming a $120 \mathrm{~m}$ drop in sea level. We also tested the mean proposed changes in phytoplankton stoichiometry as reported from phytoplankton physiology models under 
Table 1. The major characteristics of the different representations of ocean circulation used during this study.

\begin{tabular}{lrrrr}
\hline Simulation & $\begin{array}{r}\text { NADW Max } \\
(\mathrm{Sv})^{\mathrm{a}}\end{array}$ & $\begin{array}{r}\text { NADW Depth } \\
(\mathrm{m})^{\mathrm{a}}\end{array}$ & $\begin{array}{r}\text { AABW Max } \\
(\mathrm{Sv})^{\mathrm{b}}\end{array}$ & $\begin{array}{r}\text { AABW at Depth } \\
(\mathrm{Sv})^{\mathrm{b}}\end{array}$ \\
\hline Pre-industrial & 12 & 2500 & -5 & -3 \\
CircA & 5 & 1750 & -4 & -1 \\
CircB & 6 & 2000 & -7 & -4 \\
CircC & 22 & bottom & -13 & -8 \\
CircD & 16 & 3250 & -12 & -4.5 \\
CircE & 18 & 4500 & -10 & -5.5 \\
\hline
\end{tabular}

a "NADW Max" is the maximum value of the meridional stream function between 500 and $1500 \mathrm{~m}$ and $30^{\circ} \mathrm{N}$ to $50^{\circ} \mathrm{N}$. "NADW depth" is the depth at which the stream function is zero.

b "AABW Max" is the minimum value of the meridional stream function between $55^{\circ} \mathrm{S}$ to $75^{\circ} \mathrm{S}$ (circumpolar), whereas "AABW at depth" is minimum value of the stream function at $3000 \mathrm{~m}$ (also between $55^{\circ} \mathrm{S}$ to $75^{\circ} \mathrm{S}$, to give an indication as to the depth of ventilation by AABW).

LGM climate, which results in a $12 \%$ increase in the mean phytoplankton $\mathrm{C} / \mathrm{N}$ ratio (Omta et al., 2006).

OGCM LGM simulations using the IPSL model employ a modified land/sea mask, accounting for topography and ice sheets (Peltier, 2004). Atmospheric concentrations of $\mathrm{CO}_{2}, \mathrm{CH}_{4}$ and $\mathrm{N}_{2} \mathrm{O}$ for radiative forcing were $185 \mathrm{ppm}$, $350 \mathrm{ppb}$ and $200 \mathrm{ppb}$, respectively, with orbital parameters from $21 \mathrm{kyr}$ BP (following the PMIP2 protocol, http://pmip2. lsce.ipsl.fr) and this climate impacts the properties of the ocean (in terms of temperature and salinity). Our experiments are designed to test the impact of different LGM overturning circulations on carbon isotopes, ocean biogeochemistry and $p \mathrm{CO}_{2 \mathrm{~atm}}$. While in this particular study, alternative circulations are obtained via changes in surface freshwater forcing of the ocean, these could have arisen from a number of climatic forcings, such as other freshwater fluxes or changes in winds. For example, the overturning circulations could also represent the postulated changes induced by latitudinal changes in southern hemisphere westerly winds, especially with regards to the SO (e.g., Toggweiler et al., 2006). We used the resulting circulations (Table 1) to force PISCES offline (i.e., the circulations were constant for the duration of the experiments). Before running each simulation, we remove $0.4 \%$ ofrom oceanic $\delta^{13} \mathrm{C}_{\text {DIC }}$ (by decreasing DI ${ }^{13} \mathrm{C}$ ) and add a further 1 psu to salinity (on top of LGM climate related changes) to account for changes in land biosphere carbon and sea level, respectively. We also increased nutrient stocks by $3 \%$ to account for the change in sea level in the first year of simulation (we note that we did not change DIC or alkalinity). We performed integrations of 500-years for each experiment (except those concerned with carbon-14, which ran for 3000 years), following a 3000-year spin-up under preindustrial conditions (Tagliabue and Bopp, 2008). Initially, we ran PISCES with LGM dust under a pre-industrial (PI) circulation and then with each "LGM" circulation scheme (Table 1) in turn, evaluating the simulated $\Delta \delta^{13} \mathrm{C}_{\text {DIC }}$ (LGMPI) against 133 observations from benthic foraminifera, as well as evaluating simulated $\Delta^{14} \mathrm{C}$ against previously published data. Subsequently, we then examined the impact on ocean biogeochemistry and $p \mathrm{CO}_{2 \mathrm{~atm}}$ of the LGM overturning circulation that is able to reproduce carbon isotope observations.

We also examined the relationship between ocean circulation and $\delta^{13} \mathrm{C}_{\text {DIC }}$ using the IC-model CLIMBER-2 (see Sect. 2.3). To that end, we made a number of idealised freshwater additions to the Northern and Southern Hemispheres under LGM climate and examined the impact on ocean carbon-13 distributions after simulations of 20000 years. This permits us to evaluate the robustness of our findings from the OGCBM, which, while more complex than CLIMBER-2 (in terms of its spatial resolution and biogeochemical processes), necessitates shorter simulation durations.

LGM and pre-industrial $\delta^{13} \mathrm{C}_{\text {DIC }}$ data from benthic foraminifera are from the MOTIF database (http://motif.lsce. ipsl.fr). We removed data without a complete PI-LGM pair, leaving 133 paired observations to compare with our model results.

\section{Results and discussion}

\subsection{LGM ocean carbon-13}

While increasing dust iron supply under a pre-industrial circulation reduces deep-water $\delta^{13} \mathrm{C}_{\mathrm{DIC}}$, due to an increased export of organic matter with light $\delta^{13} \mathrm{C}$ values, its impact remains too local and too slight to explain the observations alone (Fig. 1a, Table 2). Stimulation of carbon export (see Table 3 and Sect. 3.2) in the iron limited SO is responsible for a slight decrease in deep-water $\delta^{13} \mathrm{C}_{\text {DIC }}$ in the SO and a slight increase in northern latitudes (Fig. 1a). Increased LGM overturning (CircC, CircD, and CircE) drives a larger change in $\Delta \delta^{13} \mathrm{C}_{\mathrm{DIC}}$, but since enhanced mixing of enriched 
Table 2. Statistical comparison of model simulation glacial-interglacial change in ocean $\delta^{13} \mathrm{C}_{\mathrm{DIC}}$ with observations from benthic foraminifera collated in the MOTIF database (values compared at the identical latitude, longitude and depth as the observations, see Table 1 for details on model simulations).

\begin{tabular}{|c|c|c|c|c|c|}
\hline \multirow[b]{2}{*}{ Simulation } & \multicolumn{4}{|c|}{ Entire Ocean ${ }^{\mathrm{a}}$} & \multirow{2}{*}{$\begin{array}{r}>3 \mathrm{~km}^{\mathrm{a}} \\
\text { Mean }\end{array}$} \\
\hline & Correlation $(R)$ & Slope & Intercept & Mean & \\
\hline Data & 1 & 1 & $0 \%$ & $-0.34 \pm 0.45 \% \circ$ & $-0.64 \pm 0.33 \% o$ \\
\hline PI+Dust & 0.49 & 0.03 & $0.06 \%$ o & $0.05 \pm 0.03 \% \circ$ & $0.04 \pm 0.02 \% \circ$ \\
\hline CircA & 0.60 & 0.31 & $-0.19 \%$ & $-0.31 \pm 0.20 \%$ o & $-0.42 \pm 0.13 \%$ \\
\hline CircB & 0.28 & -0.08 & $-0.12 \%$ & $-0.16 \pm 0.13 \% \circ$ & $-0.14 \pm 0.13 \% o$ \\
\hline CircC & -0.48 & -0.28 & $-0.03 \%$ & $0.06 \pm 0.26 \%$ & $0.27 \pm 0.28 \%$ \\
\hline CircD & -0.31 & -0.13 & $-0.04 \%$ & $-0.02 \pm 0.20 \% o$ & $0.06 \pm 0.25 \% \circ$ \\
\hline CircE & -0.38 & -0.22 & $-0.05 \%$ & $0.01 \pm 0.26 \%$ & $0.20 \pm 0.28 \% o$ \\
\hline
\end{tabular}

a There are 133 valid data points in the entire ocean, with 60 of these at or below $3 \mathrm{~km}$.

Table 3. The impact of modified ocean circulation and dust input (Sim) on the change in atmospheric $p \mathrm{CO}_{2}\left(\Delta p \mathrm{CO}_{2}, \mathrm{ppm}\right)$, global annual carbon export (at $100 \mathrm{~m}, \mathrm{Cex}, \mathrm{PgC}$ ) and the proportion of total $\mathrm{PO}_{4}$ in the preformed pool (Ppre, assuming a $\mathrm{P}: \mathrm{O}_{2}$ ratio of 140), as well as for the Southern Ocean (SO, south of $40^{\circ} \mathrm{S}$ ). The proportion of total $\mathrm{PO}_{4}$ in the regenerated pool (i.e., Preg) is $1-\mathrm{Ppre}$. We require a $\Delta p C \mathrm{CO}_{2}$ of $50 \mathrm{ppm}$ (see text).

\begin{tabular}{lrrrrr}
\hline \multirow{2}{*}{ Sim } & $\begin{array}{r}\Delta p \mathrm{CO}_{2} \\
\mathrm{ppm}^{\mathrm{a}}\end{array}$ & $\begin{array}{r}\mathrm{Cex}, \\
\mathrm{PgC}(\%)\end{array}$ & $\begin{array}{r}\text { Po Cex }, \\
\mathrm{PgC}(\%)\end{array}$ & $\begin{array}{r}\text { SO } \\
\text { Ppre }\end{array}$ \\
\hline PI & - & 7.97 & 0.455 & 2.36 & 0.543 \\
+ LGM dust & -11 & 7.77 & 0.438 & 2.72 & 0.504 \\
& & $(-2.6)$ & & $(+15)$ & \\
CircA + PI dust & -3.5 & 7.24 & 0.487 & 2.35 & 0.575 \\
& & $(-9)$ & & $(-0.3)$ & \\
CircA + LGM dust & -16 & 7.17 & 0.471 & 2.65 & 0.540 \\
& & $(-10)$ & & $(+12)$ & \\
CircA + LGM dust +CN & -25 & 7.02 & 0.475 & 2.90 & 0.543 \\
& & $(-12)$ & & $(+23)$ & \\
\hline
\end{tabular}

a Pre industrial (PI) atmospheric $p \mathrm{CO}_{2}$ is $278 \mathrm{ppm}$.

surface waters with depleted deep waters results, the change is opposite to that observed (i.e., increased at depth, relative to the surface, and vice-versa, Fig. 1d-f, Table 2). On the other hand, under diminished north Atlantic (NA) ventilation (CircA and $\mathrm{CircB}$ ) an excellent regional agreement with NA $\Delta \delta^{13} \mathrm{C}_{\text {DIC }}$ observations results (Figs. $1 \mathrm{~b}$ and $\mathrm{c}, 2$, Table 2, with $R=0.73$ ). The change in the NA $\delta{ }^{13} \mathrm{C}_{\text {DIC }}$ gradient is robustly related to changes in either the speed or depth of NA ventilation (across all simulations, Fig. 3). This relationship is also remarkably consistent when examined with CLIMBER-2 (Fig. 3), which supports the statement from the OGCBM that NA ventilation is the dominant process governing the NA $\delta^{13} \mathrm{C}_{\text {DIC }}$ vertical gradient (as reconstructed from benthic foraminifera). Using the OGCBM relationship, the observed $0.49 \%$ increase in gradient requires a $59 \%$ or $68 \%$ reduction in overturning speed, or depth, respectively. Since simulations with different degrees of SO ventilation (CircA and CircB) both reproduce NA $\Delta \delta^{13} \mathrm{C}_{\text {DIC }}$ (Fig. $1 \mathrm{~b}$ and c), we suggest local (i.e., NA) forcings predominate and the role of Antarctic processes are of second order. Unfortunately, in all the circulations tested in this study, increased NA ventilation speed was always accompanied by a deepening of ventilation (and vice-versa, Table 1), leaving us unable to isolate their separate effects. Nevertheless, assuming modern overturning is $18 \mathrm{~Sv}$ and ventilates to $4000 \mathrm{~m}$ (Talley et al., 2003), a LGM NA ventilation of $7 \mathrm{~Sv}$ to $1300 \mathrm{~m}$ would satisfy $\Delta \delta^{13} \mathrm{C}_{\text {DIC }}$ observations.

Turning to the SO, deep-water $\delta^{13} \mathrm{C}_{\text {DIC }}$ increases when the necessary reduction in NA ventilation is accompanied by increased SO ventilation (CircB), as suggested by some LGM studies, (Curry and Oppo, 2005; Brovkin et al., 2007), which is contrary to observations (Fig. 1c, Table 2). We find that only lesser SO ventilation (mostly in the Atlantic and Indian ocean sectors) at the LGM can reproduce the observed depletion in deep $\delta^{13} \mathrm{C}_{\text {DIC }}$ (CircA, Fig. 1b). Furthermore, simulated bottom $\Delta \delta^{13} \mathrm{C}_{\text {DIC }}$ highlights the widespread impact of elevated $\mathrm{SO}$ ventilation (CircB) on $\Delta \delta^{13} \mathrm{C}_{\text {DIC }}$ (Fig. 2b) and, since dust is insufficient (there is only a weak change 


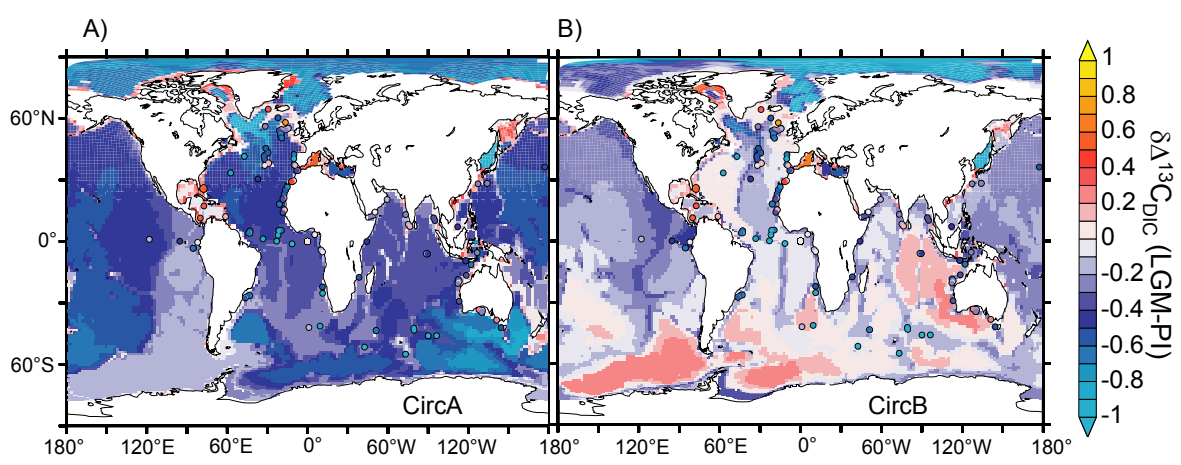

Fig. 2. The change in $\delta^{13} \mathrm{C}_{\text {DIC }}(\%$ ) between the pre-industrial and LGM periods (LGM-PI) from the bottom most model grid cell (i.e. at the sediment - water interface), with circles representing benthic foraminifera $\Delta \delta^{13} \mathrm{C}_{\text {DIC }}$ observations from the MOTIF database. In this figure, we highlight the role of decreased $(\mathbf{A}$, CircA) and increased $(\mathbf{B}$, CircB) Southern Ocean ventilation in conjunction with a reduction in North Atlantic ventilation. The scale is the same as for Fig. 1.

in deep-water $\delta^{13} \mathrm{C}_{\mathrm{DIC}}$ due to elevated SO export, see further discussion of the export response in Sect. 3.2), confirms the necessity for reduced LGM SO ventilation (CircA) in order to satisfy the deep $\delta^{13} \mathrm{C}_{\mathrm{DIC}}$ observational constraint (Fig. 2a). In contrast to previous IC-models (which assume increased SO ventilation, Brovkin et al., 2007), our OGCBM demonstrates the far-field effects of greater $\mathrm{SO}$ ventilation on $\Delta \delta^{13} \mathrm{C}_{\text {DIC }}$ and its discord with observations (CircB, Fig. 2b). Indeed, additional tests with CLIMBER-2, show that when we reduce SO ventilation, the deep SO $\delta^{13} \mathrm{C}_{\text {DIC }}$ declines (by $\left.0.03 \% \circ \mathrm{Sv}^{-1}\right)$ in line with observations. Finally, $\Delta^{14} \mathrm{C}$ simulations (performed offline for 3000 years) also demonstrate that only CircA captures the observed increase in deep water ages (Robinson et al., 2005; Sikes et al., 2000), with enhanced SO ventilation (CircB) causing earlier ages for the deep ocean, in contrast to observations (Fig. 4). While CircA has reduced overall SO ventilation, we note that this response is heterogeneous in space, with a shift in ventilation sites and slight increases in ventilation in some places (such as the Ross Sea, which explains the weaker $\delta^{13} C_{\text {DIC }}$ change in this region (Fig. 2a).

Overall, only reduced NA and SO ventilation, isolating the deep-ocean, can reproduce LGM $\delta^{13} \mathrm{C}_{\mathrm{DIC}}$, as well as $\Delta^{14} \mathrm{C}$, observations. The reduced SO ventilation at the LGM, that is necessitated by $\delta^{13} \mathrm{C}_{\mathrm{DIC}}$ and $\Delta^{14} \mathrm{C}$ observations, might have arisen from the postulated equatorward shift in Southern Hemisphere westerly winds (Toggweiler et al., 2006), although this is not the forcing which we have used in this study. Our results regarding the nature of the LGM overturning circulation agree with earlier box model studies (Toggweiler, 1999), whereas previous CLIMBER-2 simulations with greater SO ventilation cannot replicate $\mathrm{SO} \delta^{13} \mathrm{C}_{\mathrm{DIC}} \mathrm{ob}-$ servations (Brovkin et al., 2007). Similarly, a variety of other proxies $\left({ }^{18} \mathrm{O}, \mathrm{Cd} / \mathrm{Ca},{ }^{15} \mathrm{~N} /{ }^{14} \mathrm{~N}\right.$, and $\left.{ }^{231} \mathrm{~Pa} /{ }^{230} \mathrm{Th}\right)$ support a poorly ventilated LGM deep-ocean (e.g., Robinson et al., 2005; Sikes et al., 2000; Sigman et al., 2004; Francois et al., 1997; Adkins et al., 2005; Marchitto and Broecker,

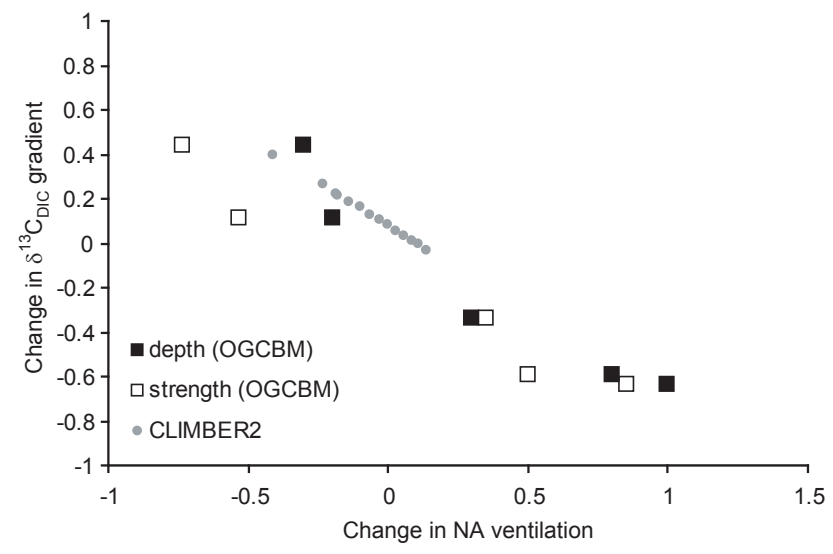

Fig. 3. The relationship between the fractional change in either the intensity (open squares), or depth (filled squares), of North Atlantic overturning (defined as for Table 1) and the change in the upper $(0-2000 \mathrm{~m})$ to deep $(3000-5000 \mathrm{~m}) \delta^{13} \mathrm{C}_{\text {DIC }}$ gradient (\%o, where a positive value implies an increase in the gradient at LGM) in the Atlantic between 30 and $80^{\circ} \mathrm{N}$ for all simulations listed in Table 1. The relationships are described by $\Delta \delta^{13} \mathrm{C}_{\mathrm{DIC}}$ gradient $=-0.666(\Delta \mathrm{NA}$-ventilation $)-0.145 \quad(R=-0.98) \quad$ and $\delta^{13} \mathrm{C}_{\text {DIC }}$ gradient $=-0.776(\Delta \mathrm{NA}$-ventilation $)+0.045 \quad(R=-0.96)$ for ventilation strength and depth, respectively. Superimposed (in grey) is the impact of changes in NA ventilation on the $\delta^{13} \mathrm{C}_{\text {DIC }}$ gradient in the IC-model CLIMBER-2 $\left(\delta^{13} \mathrm{C}_{\mathrm{DIC}}\right.$ gradient $=-0.771(\Delta \mathrm{NA}$-ventilation $)+0.079, R=-0.999$, calculated in the same fashion as for the 3-D OGCBM), which highlights that the fundamental relationship between NA ventilation and the $\delta^{13} \mathrm{C}_{\mathrm{DIC}}$ gradient is robust and not specific to the OGCBM. Observations show an increase in gradient of $0.49 \%$ for the same region. We note that our depth ranges for the $\delta^{13} \mathrm{C}_{\text {DIC }}$ gradient were chosen to examine the effect of circulation on $\delta{ }^{13} \mathrm{C}_{\mathrm{DIC}}$, rather than the biological pump. Changes in NA overturning for CLIMBER-2 were calculated in the same fashion as for the OGCBM. 


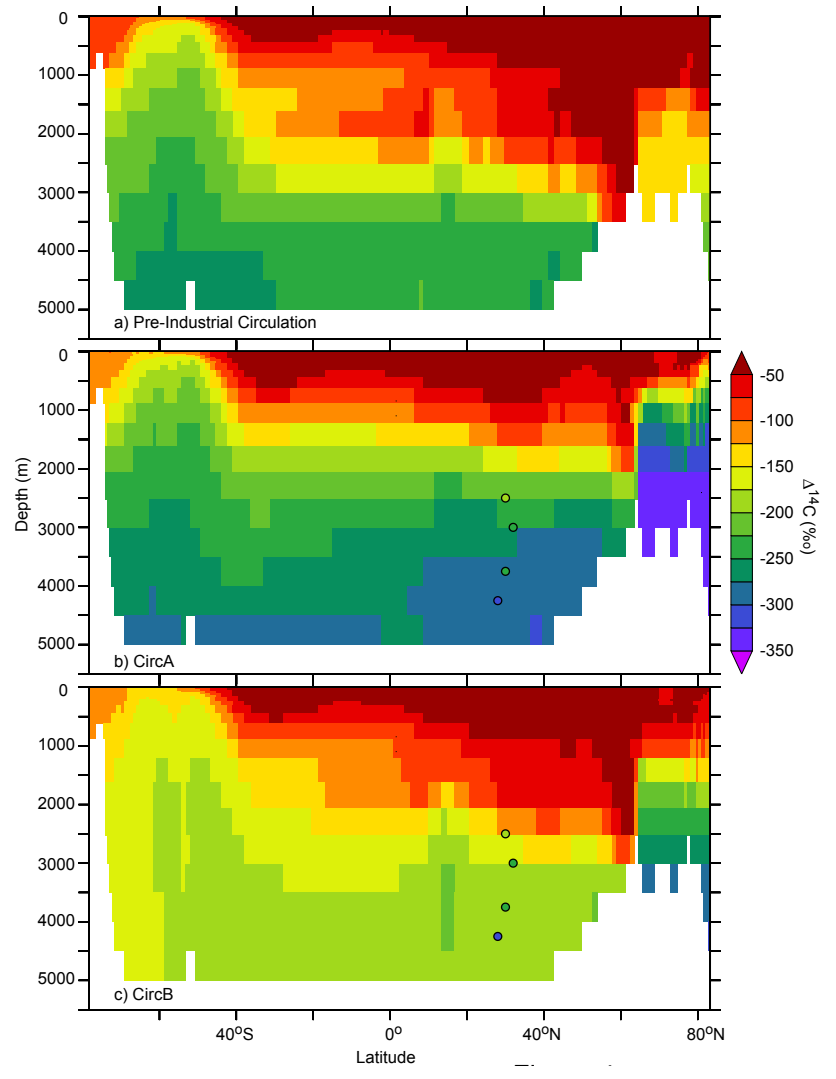

Fig. 4. $\Delta^{14} \mathrm{C}(\%$ o) for (a) the pre-industrial circulation, (b) CircA and (c) CircB presented as an Atlantic zonal mean (Where $\left.\left.\Delta^{14} \mathrm{C}=1000^{*}\left(\left(\mathrm{DI}^{14} \mathrm{C} / \mathrm{DIC}\right)-1\right)\right)\right)$. We include LGM $\Delta^{14} \mathrm{C}$ data collected from the western North Atlantic (Robinson et al., 2005) as circles for (b) and (c), which demonstrates that only CircA (which has reduced SO ventilation, Table 1) captures the increased deepwater ages present in the data. The GLODAP estimation (Key et al., 2004) of the pre-industrial $\Delta^{14} \mathrm{C}$ for the Atlantic basin (zonal mean) is presented in Supplementary Fig. 2 (see http://www.clim-past.net/ 5/695/2009/cp-5-695-2009-supplement.pdf).

2006; Keigwin and Boyle, 2008). Surface waters were, thus, enriched with carbon-13 and deep waters more strongly reflected the light carbon introduced from organic matter remineralisation. Accordingly, CircA provides the best statistical fit to the $133 \Delta \delta{ }^{13} \mathrm{C}_{\text {DIC }}$ observations from benthic foraminifera $(R=0.6, p<0.001)$ and reproduces the greater reduction in $\delta^{13} \mathrm{C}_{\text {DIC }}$ at depths greater than $3 \mathrm{~km}$ (Table 2).

Deep-water oxygen responds to the changes in ocean circulation and biology. In response to LGM dust, the greater export of organic matter in the SO results in reduced deepwater oxygen (Fig. 5a), which are then transported northward and throughout the SO by the abyssal ocean circulation. The reduced ventilation present in CircA that is necessary to reconcile $\delta^{13} \mathrm{C}_{\text {DIC }}$ observations elevates global suboxia when it acts in conjunction with LGM dust (defined as $\mathrm{O}_{2}<5 \mu \mathrm{M}$ ) 3 -fold, which should ostensibly increase denitrification rates and this depletes the oceanic fixed nitrogen inventory. More-

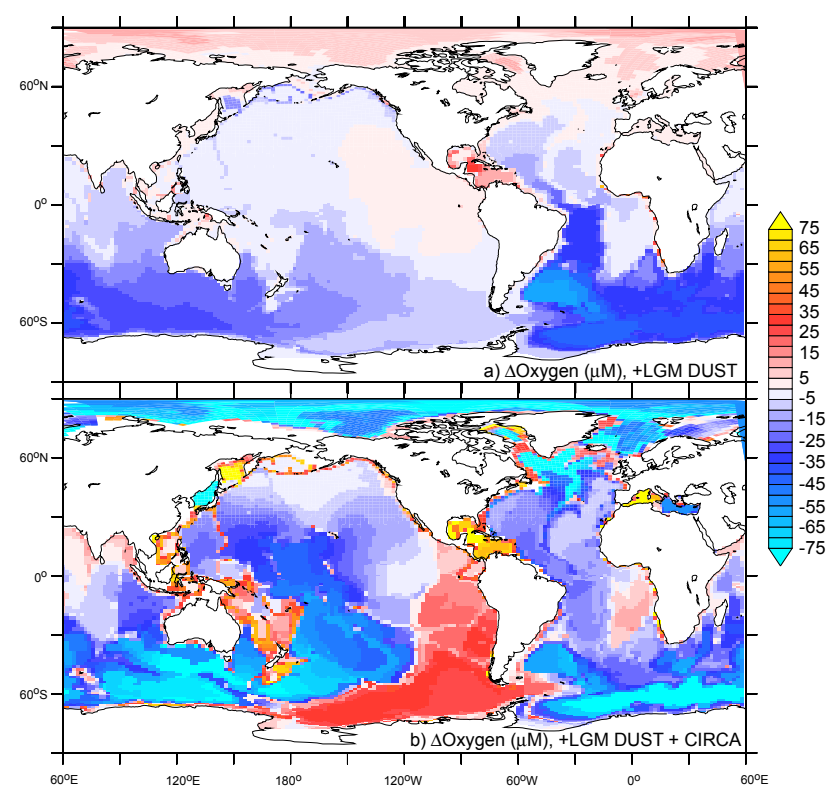

Fig. 5. The change in bottom water oxygen concentrations $\left(\mu \mathrm{M} \mathrm{O}_{2}\right.$, relative to the PI) in response to (a) LGM dust and (b) Circ A+LGM dust (see Table 1).

over, the reduced overturning rate necessitated by carbon-13 and carbon-14 measurements might possibly also inhibit the degree of compensation (in terms of the oceanic fixed $\mathrm{N}$ inventory) by $\mathrm{N}_{2}$ fixation (Tagliabue et al., 2008). Nevertheless, despite a sluggish PI circulation (Table 1) CircA and LGM dust did not drive total anoxia at depth in all places (Fig. 5b). In fact, colder temperatures, reduced subduction of oxygen-rich surface waters and shifts in SO ventilation sites associated with CircA and the LGM climate can actually elevate deep oxygen in some regions. These include modern denitrification sites (e.g., eastern Pacific and Arabian Sea, Fig. 5b), consistent with observations of reduced LGM denitrification therein (Ganeshram et al., 2000). Overall, oxygen declined in most all of the deep ocean during our experiments, but since a spatial reorganisation of denitrification sites will likely follow modified LGM circulation (especially if it impacts deep water formation sites), a reduction in denitrification at a modern denitrification site might not necessary imply reduced global LGM denitrification.

\subsection{LGM atmospheric $\mathrm{CO}_{2}$}

A circulation that reproduces LGM $\delta^{13} \mathrm{C}_{\text {DIC }}$ lowers $p \mathrm{CO}_{2 \mathrm{~atm}}$ by $3.5 \mathrm{ppm}$ (CircA alone, Table 3 ). Since the included temperature/salinity changes associated with LGM climate increase $\mathrm{CO}_{2}$ uptake and typically reduce $p \mathrm{CO}_{2 \mathrm{~atm}}$ by $\sim 15$ ppm (e.g., Brovkin et al., 2007), this means that the lesser ventilation necessary to reconcile $\delta^{13} \mathrm{C}_{\mathrm{DIC}}$ observations actually causes increased $p \mathrm{CO}_{2 \mathrm{~atm}}$. This is because vertical nutrient supply to surface waters is reduced and 
export production declines, which increases preformed nutrients (Table 3). Overall, the increased solubility pump that results from the LGM climate is almost entirely compensated for by a reduced biological pump and results in a net $3.5 \mathrm{ppm}$ $p \mathrm{CO}_{2 \mathrm{~atm}}$ reduction. Our OGCBM represents the spatial variability in $\mathrm{CO}_{2}$ fluxes, as well as circulation-biogeochemistry feedbacks and demonstrates that although $\delta^{13} \mathrm{C}_{\text {DIC }}$ observations require less well-ventilated glacial ocean (which might have arisen from a northward redistribution of westerly winds in the Southern Hemisphere), this cannot drive a significant portion of the LGM $p \mathrm{CO}_{2 \mathrm{~atm}}$ (Table 3). In addition, reduced $\mathrm{SO}$ ventilation also retards the vertical supply of alkalinity to surface waters and this decreased surface alkalinity also contributes to the weak impact of CircA on $p \mathrm{CO}_{2 \mathrm{~atm}}$. The weak response in terms of $p \mathrm{CO}_{2 \mathrm{~atm}}$ that results from CircA is due to the counteracting effects of the oceanic solubility, carbonate and biological pumps that are represented by our OGCBM.

Despite contributing little to $\delta^{13} \mathrm{C}_{\mathrm{DIC}}$, LGM dust does reduce $p \mathrm{CO}_{2 \mathrm{~atm}}$. While iron fertilisation of SO export elevates local $\mathrm{CO}_{2}$ uptake, total global export declines due to reduced low latitude nutrient supply (Dust+PI circulation, Table 3). Nevertheless, the SO is an effective control of $p \mathrm{CO}_{2 \text { atm }}$ (Marinov et al., 2006) and the $15 \%$ enhancement of export therein and overall reduction in preformed nutrients reduces $p \mathrm{CO}_{2 \text { atm }}$ by $11 \mathrm{ppm}$ (Table 3 ). This is $>3$-fold lower than the $35 \mathrm{ppm}$ found when ICmodels are forced by arbitrary increases in SO productivity (Brovkin et al., 2007), highlighting the importance of explicitly representing dust iron and other limiting factors (such as light/macronutrients/physiology) when appraising the impact of LGM dust.

Our OGCBM has a relatively low sensitivity to the large increase in dust iron supply, which results from phytoplankton physiological and ocean circulation processes. We find that the OGCBM primary productivity response to the additional dust iron is tempered by the $60 \%$ increase in the physiological (carbon specific) iron demand that follows elevated iron supply (the $\mathrm{Fe} / \mathrm{C}$ ratio). A greater iron demand results from the up regulation of iron requiring processes by the phytoplankton that increases the $\mathrm{Fe} / \mathrm{C}$ ratio (Sunda and Hunstman, 1997). In addition, increasing dust deposition of iron also promotes a floristic shift in phytoplankton species composition towards diatoms (by $25 \%$, as seen during iron enrichment experiments, deBaar et al., 2005), which have a greater iron demand. Explicitly representing these 2 processes, as well as the role of macronutrients and light in limiting phytoplankton growth (in the northern and southern part of the Southern Ocean, respectively) retards the response of ocean biology to LGM dust deposition. This explains why our OGCBM has a lower sensitivity to dust than previous OGCBMs that did not include such effects (Bopp et al., 2003) or IC-models that do not explicitly account for iron (Brovkin et al., 2007). Compensatory changes in carbon export at low latitudes that result from modified nutrient utilization at high latitudes (Tagliabue et al., 2008) are also important in understanding the impact on the global carbon cycle.

In addition to the effects of the solubility and biological pumps, $p \mathrm{CO}_{2 \text { atm }}$ can be impacted by modifications to the relative export of alkalinity that follow dust driven changes in high latitude utilization of silicic acid (e.g., Matsumoto and Sarmiento, 2008). We find that LGM dust reduces SO diatom silicification (the $\mathrm{Si} / \mathrm{C}$ ratio) by $12 \%$ and silicic acid "leakage" to low latitudes does promote diatom productivity (over calcifiers), which reduces the relative export of alkalinity by $7 \%$ globally. As suggested by Matsumoto and Sarmiento (2008), this is despite a $6 \%$ reduction in absolute biogenic silica export at low latitudes (between $40^{\circ} \mathrm{S}-$ $40^{\circ} \mathrm{N}$ ) that might be measured in a sediment core. However, since additional dust also increases SO diatom abundance (see above) and hence absolute silicic acid utilisation, low latitude supply is reduced (in absolute terms). This explains the small changes to relative alkalinity export that likely contribute $<1 \mathrm{ppm}$ to $\Delta p \mathrm{CO}_{2 \text { atm }}$ (Matsumoto and Sarmiento, 2008). Nevertheless, it should be noted that even our relatively complex OGCBM only describes 2 generic phytoplankton (diatoms and nanophytoplankton) and the potential for small diatoms (and possibly other species) to outcompete calcifiers in the nutrient-poor low latitudes might not be adequately represented.

Figure 6 presents the spatial distribution of the proportional change in carbon export at $100 \mathrm{~m}$ from the OGCBM (LGM dust under PI circulation and LGM dust under CircA, Table 1) that is overlain with a qualitative appraisal of the change in carbon export at the LGM from a recent data-based compilation (Kohfeld et al., 2005). It should be borne in mind that the data compilation aggregates estimates from a variety of different proxies to assign 'scores' regarding LGM export (Kohfeld et al., 2005) and is thus necessarily qualitative. On the other hand, the OGCBM presents export at $100 \mathrm{~m}$, which is not a precise analogue to the data. The data presents some obvious trends: increased export in the LGM sub-Antarctic region, with lesser export in poleward latitudes and increased export in the north Atlantic. At low latitudes, the trend in the Pacific appears equivocal, while in the tropical Atlantic export increased at modern upwelling sites near Africa and probably increased throughout the tropical Atlantic basin, although some cores suggest reductions (Kohfeld et al., 2005).

Our results suggest that LGM dust is the driver of increased export in the South Atlantic, while reduced export in the Antarctic sector (i.e., south of the Polar Front) of the Southern Ocean is a result of circulation/sea-ice changes (although we find the transition from increased to decreased export occurs poleward of where the data suggests, Fig. 6). Increased export in the North Atlantic is a result of circulation changes in conjunction with LGM dust deposition, while the OGCBM trend in the Equatorial Pacific is equivocal (in accord with the data, Fig. 6). While both OGCBM candidates 


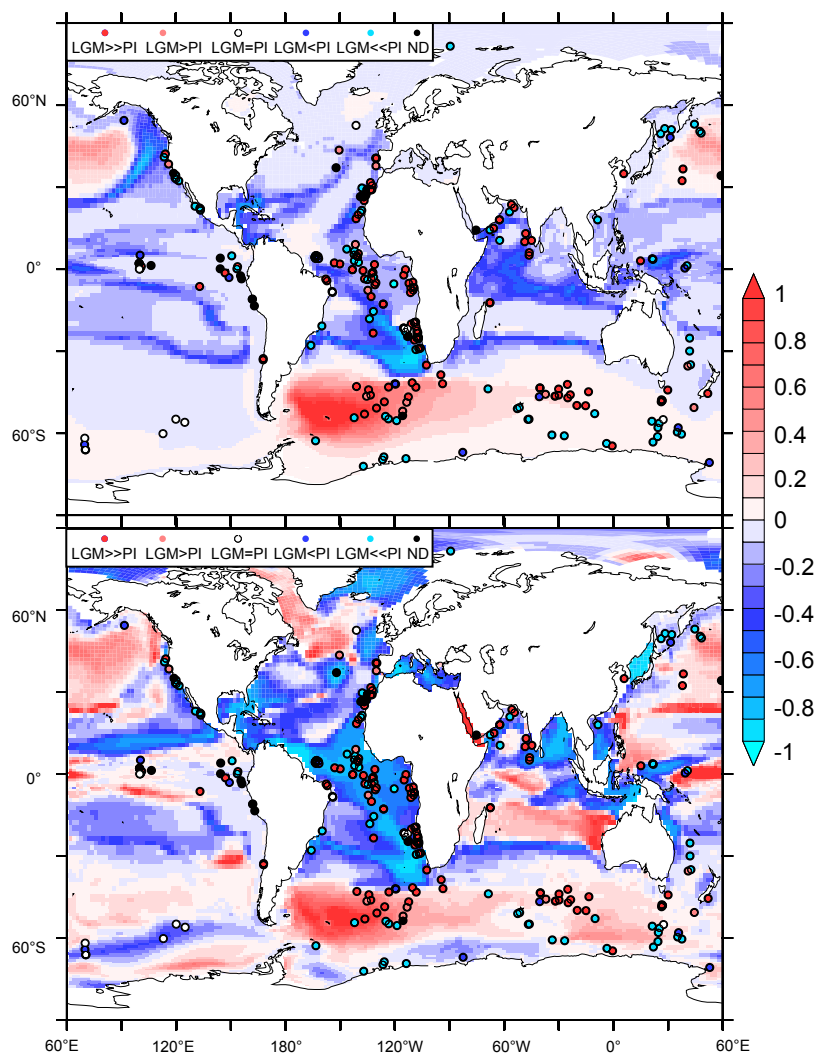

Fig. 6. The proportional change in organic carbon export (at $100 \mathrm{~m}$ ) from the OGCBM (relative to the pre-industrial) for (a) LGM dust added to a PI circulation and (b) LGM dust added to CircA. Circles represent a data compilation of the qualitative change in export production at the LGM from Kohfeld et al. (2005). We plot the change in export at the LGM data on the same scale as the OGCBM results where (for the data points), $-1=$ decrease, $-0.5=$ slight decrease, $0=$ no trend,$+0.5=$ slight increase and $+1=$ increase (black circles represent data points where the LGM trend in export was equivocal). Note that the OGCBM results represent the proportional change in organic carbon export at $100 \mathrm{~m}$ and can therefore only be compared with the data (which rely on a variety of methods) in a qualitative sense.

(LGM dust and CircA+LGM dust) suggest reduced export in the tropical Atlantic, the trend in the data is unclear with increased, slightly increased, and decreased export all present in the data synthesis (Fig. 6). Reduced vertical nutrient supply (during CircA) and increased nutrient utilization in the Southern Ocean (following LGM dust) both act to decrease the nutrient concentrations and, thus, carbon export in the tropics. This negative effect on nutrient supply to the tropics is only enhanced when LGM dust acts alongside CircA. If tropical LGM export did increase as suggested by Kohfeld et al. (2005), then additional processes (e.g., elevated nutrient supply from rivers, changes in stoichiometry or species composition) might be important in compensating for the decline in nutrients that results from dust (greater high latitude macronutrient utilization) and circulation (less ocean ventilation) changes that occurred at the LGM.

LGM dust causes a $16 \mathrm{ppm}$ decline in $p \mathrm{CO}_{2 \text { atm }}$ if added to CircA (Table 3), which is an additional $1.5 \mathrm{ppm}$ (or 14\%), relative to the separate effects of CircA ( $-3.5 \mathrm{ppm})$ and LGM dust $(-11 \mathrm{ppm})$. Although dust fertilizes SO export in CircA less than for the pre-industrial circulation (12\% instead of $15 \%$, Table 3 , due to reduced vertical nutrient supply), the deep-water sequestration of exported carbon is enhanced due its greater residence time at depth (illustrated by the impact on carbon-14 of CircA, Fig. 4). Consequently, while circulation changes might not explain LGM $p \mathrm{CO}_{2 \mathrm{~atm}}$, the reduced ventilation necessitated by $\delta^{13} \mathrm{C}_{\text {DIC }}$ can potentially amplify the impact of dust or other biogeochemical forcings. Including a $12 \%$ increase in LGM planktonic $\mathrm{C} / \mathrm{N}$ ratios (Omta et al., 2006) in combination with LGM dust and CircA reduces $p \mathrm{CO}_{2 \mathrm{~atm}}$ by another $9 \mathrm{ppm}$ (by $25 \mathrm{ppm}$ in total, Table 3). Interestingly, adding modified stoichiometry to CircA with LGM dust causes preformed nutrients to change little, despite lowering $p \mathrm{CO}_{2}$ atm further (Table 3), which demonstrates that preformed nutrients are decoupled from changes in $p \mathrm{CO}_{2 \text { atm }}$ if the overall $\mathrm{C} / \mathrm{N}$ stoichiometry is modified.

\section{Synthesis}

Overall, we capture $25 \mathrm{ppm}$ of the required $50 \mathrm{ppm} p \mathrm{CO}_{2 \mathrm{~atm}}$ decline (prior to carbonate compensation) and almost all of the necessary change in the $\delta^{13} \mathrm{C}_{\text {DIC }}$ gradient (Fig. 7). Using our results in combination with two observational constraints ( $p \mathrm{CO}_{2 \mathrm{~atm}}$ and the $\delta^{13} \mathrm{C}_{\mathrm{DIC}}$ gradient), we estimate that ocean circulation (CircA) explains two-thirds of the LGM $\delta^{13} \mathrm{C}_{\mathrm{DIC}}$ gradient, but $<10 \%$ of the necessary $p \mathrm{CO}_{2 \mathrm{~atm}}$ change (Fig. 7, "LGM-circulation" isoline, $-9.48 \mathrm{ppm} \% \mathrm{o}^{-1}$ ). In contrast, biogeochemical processes only explain one-third of the LGM $\delta^{13} \mathrm{C}_{\text {DIC }}$ gradient, but would have to account for $>90 \%$ of the $p \mathrm{CO}_{2 \mathrm{~atm}}$ decline (Fig. 7, "LGM-biology" isoline, $-238 \mathrm{ppm} \%{ }^{-1}$ ).

Because our shortfall of $25 \mathrm{ppm}$, or $45 \mathrm{ppm}$, considering reduced terrestrial carbon storage (Sigman and Boyle, 2000), lies along the "LGM-biology" isoline in Fig. 7, we suggest it reflects additional biogeochemical processes, which can be amplified by the LGM ocean circulation. Ocean ventilation must have declined at the LGM in order to satisfy geochemical proxy constraints (in particular $\delta^{13} \mathrm{C}_{\text {DIC }}$ and $\Delta^{14} \mathrm{C}$ ), but due to the reduced biological pump, our OGCBM suggests a lesser role for circulation changes in governing LGM $p \mathrm{CO}_{2 \mathrm{~atm}}$. Accordingly, the integrated impact of all plausible changes tested in this study (circulation, dust and stoichiometry) cannot account for the entire amplitude of the observed LGM changes in $p \mathrm{CO}_{2 \mathrm{~atm}}$. This presents a challenge to our prevailing understanding of the mechanisms behind LGM changes in $p \mathrm{CO}_{2 \mathrm{~atm}}$ and the global carbon cycle and necessitates additional biogeochemical mechanisms. For example, better representing additional biogeochemical mechanisms, 


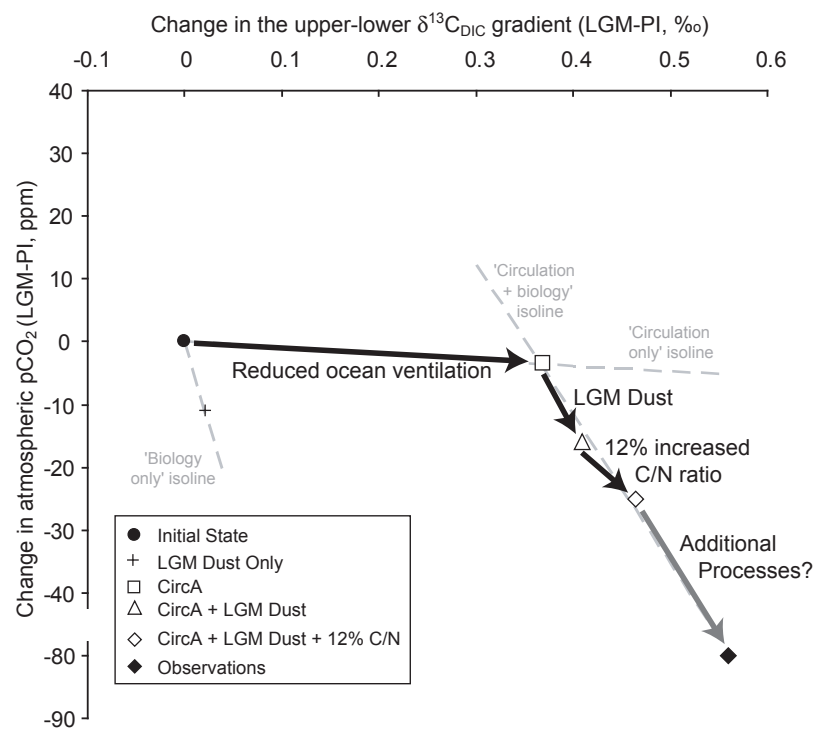

Fig. 7. A summary of the relationship between the globally averaged change in the upper $(0-2000 \mathrm{~m})$ to deep $(3000-5000 \mathrm{~m})$ gradient in $\delta^{13} \mathrm{C}_{\mathrm{DIC}}(\%)$ and the resulting change in $p \mathrm{CO}_{2 \mathrm{~atm}}$ (ppm) at the LGM for various OGCBM simulations. The black diamond denoted "observations" represents the observational constraints on the change in the $\delta^{13} \mathrm{C}_{\text {DIC }}$ gradient and $p \mathrm{CO}_{2 \mathrm{~atm}}$. Light grey dotted lines represent the "LGM-circulation", "PI-biology" and "LGM- biology" isolines, which have slopes of $-9.48,-529.4$ and $-237.68 \mathrm{ppm} \% o^{-1}$, respectively. Changes in circulation are necessary to shift the LGM $\delta^{13} \mathrm{C}_{\mathrm{DIC}}$ gradient to an appropriate value (x axis), but only changes in biological production (mediated by dust and/or changes in phytoplankton stoichiometry) can reduce $p \mathrm{CO}_{2 \mathrm{~atm}}$ markedly (y axis). The amplification effect of reduced ventilation on LGM dust is illustrated by the difference in the slopes of the "PI-biology" and "LGM-biology" isolines. Our shortfall reflects as yet unconstrained additional biogeochemical changes (see discussion in the text). We note that our depth ranges for the $\delta^{13} \mathrm{C}_{\mathrm{DIC}}$ gradient were chosen to examine the effect of circulation on $\delta^{13} \mathrm{C}_{\mathrm{DIC}}$, rather than the biological pump.

such as changes in nutrient supply from land (which remain constant in our scenarios) or shifts in phytoplankton species composition/stoichiometry that impact the export of carbon and/or alkalinity (which are represented in a relatively simplistic fashion even by our complex OGCBM), could reconcile tropical LGM export observations and lower $p \mathrm{CO}_{2 \mathrm{~atm}}$ further. The spatial and mechanistic detail of our OGCBM is much greater than prior LGM studies using box models and IC-models. Nevertheless, we may require more complex OGCBMs that also represent additional biogeochemical processes (both biotic and abiotic), as well as those dominant at high latitudes (ocean ventilation and dust deposition) in order to explain $\mathrm{LGM} p \mathrm{CO}_{2 \mathrm{~atm}}$.

\section{Conclusions}

In conclusion, we use $\delta^{13} \mathrm{C}_{\mathrm{DIC}}, \Delta^{14} \mathrm{C}$ and models of differing complexity to constrain LGM ocean circulation and while it can satisfy two-thirds of LGM $\delta^{13} \mathrm{C}_{\text {DIC }}$, biogeochemical processes were responsible for $>90 \%$ of the $p \mathrm{CO}_{2 \mathrm{~atm}}$ reduction (Fig. 3). We concur with previous studies that NA ventilation was reduced (Lynch-Stieglitz et al., 2007), but quantify its reduction. We also suggest that the impact of reduced NA ventilation was comparatively local and must have been accompanied by lesser SO ventilation to reconcile $\Delta \delta^{13} \mathrm{C}_{\text {DIC }}$ and $\Delta^{14} \mathrm{C}$ observations. Such changes may have been brought about by changes in freshwater input or westerly wind patterns. Constraining the general nature of LGM circulation explains $\delta^{13} \mathrm{C}_{\text {DIC }}$ observations, but biogeochemical changes (including increased dust deposition and modified phytoplankton stoichiometry) lowered $p \mathrm{CO}_{2 \mathrm{~atm}}$. More work is required in understanding the biogeochemical mechanisms (in addition to dust and stoichiometry) behind the final 25-45 ppm change in $p \mathrm{CO}_{2}$ atm at the LGM that is required before carbonate compensation.

Acknowledgements. This work was supported by an ANR grant (GOBAC) and an ANR-blanc grant (IDEGLACE), with computer time provided by CNRS/IDRIS and CEA/CCRT, France. We thank Kevin Arrigo and Andrew Lenton for their comments on an earlier version of this manuscript, as well as the MOTIF (http://motif.lsce.ipsl.fr) program.

Edited by: L. Beaufort

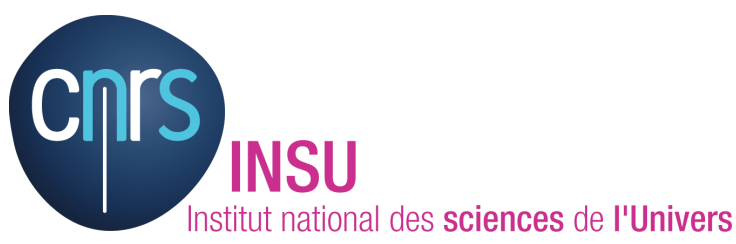

The publication of this article is financed by CNRS-INSU.

\section{References}

Adkins, J. F., Ingersoll, A. P., and Pasquero, C.: Rapid climate change and conditional instability of the glacial deep ocean from the thermobaric effect and geothermal heating, Quaternary Sci. Rev., 24, 581-594. 2005.

Alkama, R., Kageyama, M., Ramstein, G., et al.: Impact of a realistic river routing in coupled ocean-atmosphere simulations of the Last Glacial Maximum climate, Clim. Dynam., 30, 855-869, 2007.

Arsouze, T., Dutay, J.-C., Kageyama, M., Lacan, F., Alkama, R., Marti, O., and Jeandel, C.: A modeling sensitivity study of the influence of the Atlantic meridional overturning circulation on neodymium isotopic composition at the Last Glacial Maximum, Clim. Past, 4, 191-203, 2008, http://www.clim-past.net/4/191/2008/. 
Aumont, O. and Bopp, L.: Globalizing results from in situ iron fertilization studies, Global. Biogeochem. Cy., 20, GB2017, doi:10.1029/2005GB002591, 2006.

de Baar H. J. W., Boyd, P. W., Coale, K. H., et al.: Synthesis of iron fertilization experiments: From the iron age in the age of enlightenment, J. Geophys. Res, 110, C09S16, doi:10.1029/2004JC002601, 2005.

Bird, M. I., Lloyd, J., and Farquhar, G.: Terrestrial Carbon storage at the LGM, Nature 371, p. 566, 1994.

Bopp, L., Kohfeld, K. E., Le Quéré, C., and Aumont, O.: Dust impact on marine biota and atmospheric $\mathrm{CO}_{2}$ during glacial periods, Paleoceanography, 18(2), 1046, doi:10.1029/2002PA000810, 2003.

Broecker, W. S.: Ocean geochemistry during glacial time, Geochim. Cosmochim. Acta, 46, 1689-1705, 1982.

Brovkin, V., Ganopolski, A., Archer, D., and Rahmstorf, S.: Lowering of glacial atmospheric $\mathrm{CO}_{2}$ in response to changes in oceanic circulation and marine biogeochemistry, Paleoceanography, 22, PA4202, doi:10.1029/2006PA001380, 2007.

Curry, W. B. and Oppo, D. W.: Glacial water mass geometry and the distribution of $\delta^{13} \mathrm{C}$ of $\Sigma \mathrm{CO}_{2}$ in the western Atlantic Ocean, Paleoceanography, 20, PA1017, doi:10.1029/2004PA001021, 2005.

Duplessy, J. C., Shackleton, N. J., Fairbanks, R. G., Labeyrie, L., Oppo, D., and Kallel, N.: Deep water source variations during the last climatic cycle and their impact on the global deep water circulation, Paleoceanography, 3, 343-360, 1988.

Francois, R., Altabet, M. A., Yu, E. F., et al.: Contribution of Southern Ocean stratification to low atmospheric $\mathrm{CO} 2$ concentrations during the last glacial maximum, Nature, 389, 929-935, 1997.

Ganeshram, R., Pedersen, T., Calvert, S., McNeill, G., and Fontugne, M.: Glacial-Interglacial Variability in Denitrification in the World's Oceans: Causes and Consequences, Paleoceanography, 15, 361-376, 2000

Kageyama, M., Mignot, J., Swingedouw, D., Marzin, C., Alkama, R., and Marti, O.: Glacial climate sensitivity to different states of the Atlantic Meridional Overturning Circulation: results from the IPSL model, Clim. Past, 5, 551-570, 2009,

http://www.clim-past.net/5/551/2009/.

Keigwin, L. D. and Boyle, E. A.: Did North Atlantic overturning halt 17000 years ago?, Paleoceanography, 23, PA1101, doi:10.1029/2007PA001500, 2008.

Key, R. M., Kozyr, A., Sabine, C. L., Lee, K., Wanninkhof, R., Bullister, J. L., Feely, R. A., Millero, F. J., Mordy, C., and Peng, T.-H.: A global ocean carbon climatology: Results from Global Data Analysis Project (GLODAP), Global Biogeochem. Cy., 18, GB4031, doi:10.1029/2004GB002247, 2004.

Kohfeld, K. E., Le Quere, C., Harrison, S. P., and Anderson, R. F.: Role of marine biology in glacial-interglacial $\mathrm{CO}_{2}$ cycles, Science, 308, 74-78, 2005.

Kurahashi-Nakamura, T., Abe-Ouchi, A., Yamanaka, Y., and Misumi, K.: Compound effects of Antarctic sea ice on atmospheric $p \mathrm{CO}_{2}$ change during glacial-interglacial cycle, Geophys. Res. Lett., 34, L20708, doi:10.1029/2007GL030898, 2007.

Lynch-Stieglitz, J., Adkins, J. F., Curry, W. B., et al.: Atlantic meridional overturning circulation during the Last Glacial Maximum, Science, 316, 66-69, 2007.

Madec, G., Delecluse, P., Imbard, M., and Lévy, C.: OPA8.1 Ocean general circulation model reference manual, Notes Sci. Pole
Model Climate 11, Inst. Pierre-Simon Laplace, Paris, 91 pp., 1998.

Mahowald, N. M., Muhs, D. R., Levis, S., Rasch, P. J., Yoshioka, M., Zender, C. S., and Luo, C.: Change in atmospheric mineral aerosols in response to climate: Last glacial period, preindustrial, modern, and doubled carbon dioxide climates, J. Geophys. Res., 111(D10), D10202, doi:10.1029/2005JD006653, 2006.

Marchitto, T. M. and Broecker, W. S.: Deep water mass geometry in the glacial Atlantic Ocean: A review of constraints from the paleonutrient proxy $\mathrm{Cd} / \mathrm{Ca}$, Geochem. Geophys. Geosyst., 7, Q12003, doi:10.1029/2006GC001323, 2006.

Marinov, I., Gnanadesikan, A., Toggweiler, J. R., and Sarmiento, J. L.: The Southern Ocean biogeochemical divide, Nature, 441, 964-967, 2006.

Martin, J. H.: Glacial-Interglacial $\mathrm{CO}_{2}$ Change: the iron hypothesis, Paleoceanography, 5, 1-13, 1990.

Matsumoto, K. and Sarmiento, J. L.: A corollary to the silicic acid leakage hypothesis, Paleoceanography, 23, PA2203, doi:10.1029/2007PA001515, 2008.

Michel, E., Labeyrie, L., Duplessy, J.-C., Gorfti, N., Labracherie, M., and Turon, J.-L.: Could Deep Subantarctic Convection Feed the World Deep Basins during the Last Glacial Maximum?, Paleoceanography, 10(5), 927-941, 1995.

Omta, A. W., Bruggeman, J., Kooijman, S. A. L. M., and Dijkstra, H. A.: Biological carbon pump revisited: Feedback mechanisms between climate and the Redfield ratio, Geophys. Res. Lett., 33, L14613, doi:10.1029/2006GL026213, 2006.

Peltier, W. R.: Global glacial isostasy and the surface of the iceage Earth: The ICE-5G (VM2) model and GRACE, Annu. Rev. Earth Planet. Sci., 32, 111-149, 2004.

Petit, J. R., Jouzel, J., Raynaud, D., et al.: Climate and atmospheric history of the past 420000 years from the Vostok ice core, Antarctica, Nature, 399, 429-436, 1999.

Petoukhov, V., Ganopolski, A., Brovkin, V., Claussen, M., Eliseev, A., Kubatzki, C., and Rahmstorf, S.: CLIMBER-2: A climate system model of intermediate complexity. part I: Model description and performance for present climate, Clim. Dynam., 16, 117, 2000.

Robinson, L. F., Adkins, J. F., Keigwin, L. D., Southon, J., Fernandez, D. P., Wang, S.-L., and Scheirer, D. S.: Radiocarbon Variability in the Western North Atlantic During the Last Deglaciation, Science, 310, 1469-1473, 2005.

Sigman, D. M. and Boyle, E. A.: Glacial/interglacial variations in atmospheric carbon dioxide, Nature, 407, 859-869, 2000.

Sigman, D. M., Jaccard, S. J., and Haug, G. H.: Polar ocean stratification in a cold climate, Nature, 428, 59-63, 2004.

Sikes, E. L., Samson, C. R., Guilderson, T. P., and Howard, W. R: Old radiocarbon ages in the southwest Pacific at 11,900 years ago and the last glaciation, Nature, 405, 555-559, 2000.

Sunda, W. G. and Huntsman, S. A.: Interrelated influence of iron, light and cell size on marine phytoplankton growth, Nature, 390, 389-392, 1997.

Tagliabue, A. and Bopp, L.: Towards understanding global variability in ocean carbon-13, Global Biogeochem. Cy., 22, GB1025, doi:10.1029/2007GB003037, 2008.

Tagliabue, A., Bopp, L., and Aumont, O.: Ocean biogeochemistry exhibits contrasting responses to a large scale reduction in dust deposition, Biogeosciences, 5, 11-24, 2008, http://www.biogeosciences.net/5/11/2008/. 
Talley, L. D., Reid, J. L., and Robbins, P. E.: Data-based meridional overturning streamfunctions for the global ocean, J. Climate, 16, 3213-3226, 2003.

Timmermann, R., Goose, H., Madec, G., Fichefet, T., Ethé, C., and Duliére, V.: On the respresentation of high latitude processes in the ORCALIM global coupled sea ice-ocean model, Ocean Modell., 8, 175-201, 2003.
Toggweiler, J. R.: Variation of atmospheric $\mathrm{CO}_{2}$ by ventilation of the ocean's deepest water, Paleoceanography, 14, 571-588, 1999.

Toggweiler, J. R., Russell, J. L., and Carson, S. R.: Midlatitude westerlies, atmospheric $\mathrm{CO}_{2}$, and climate change during the ice ages, Paleoceanography, 21, PA2005, doi:10.1029/2005PA001154, 2006. 